\title{
Atrial Septal Aneurysm may Cause In-Hospital Recurrence of Cryptogenic Stroke
}

\author{
Ayako Kuriki ${ }^{1}$, Yuji Ueno ${ }^{2}$, Yuki Kamiya ${ }^{1}$, Takahiro Shimizu ${ }^{3}$, Ryosuke Doijiri ${ }^{4}$, Yohei Tateishi ${ }^{5}$, \\ Muneaki Kikuno ${ }^{6}$, Yoshiaki Shimada ${ }^{7}$, Hidehiro Takekawa ${ }^{8}$, Eriko Yamaguchi ${ }^{4}$, Masatoshi Koga ${ }^{6}$, \\ Masafumi Ihara ${ }^{9}$, Kenjiro Ono ${ }^{10}$, Akira Tsujino ${ }^{5}$, Koichi Hirata ${ }^{8}$, Kazunori Toyoda ${ }^{6}$, Yasuhiro Hasegawa ${ }^{3}$, \\ Nobutaka Hattori ${ }^{2}$ and Takao Urabe ${ }^{7}$
}

\author{
${ }^{1}$ Department of Neurology, Showa University Koto Toyosu Hospital, Tokyo, Japan \\ ${ }^{2}$ Department of Neurology, Juntendo University Faculty of Medicine, Tokyo, Japan \\ ${ }^{3}$ Department of Neurology, St. Marianna University School of Medicine, Kanagawa, Japan \\ ${ }^{4}$ Department of Neurology, Iwate Prefectural Central Hospital, Iwate, Japan \\ ${ }^{5}$ Department of Neurology and Strokology, Nagasaki University Hospital, Nagasaki, Japan \\ ${ }^{6}$ Department of Cerebrovascular Medicine, National Cerebral and Cardiovascular Center, Osaka, Japan \\ ${ }^{7}$ Department of Neurology, Juntendo University Urayasu Hospital, Chiba, Japan \\ ${ }^{8}$ Department of Neurology, Dokkyo Medical University, Tochigi, Japan \\ ${ }^{9}$ Department of Neurology, National Cerebral and Cardiovascular Center, Osaka, Japan \\ ${ }^{10}$ Division of Neurology, Department of Medicine, Showa University School of Medicine, Tokyo, Japan
}

Aims: Awareness of potentially embologenic diseases is critical to determining the prognosis of cryptogenic stroke. The clinical significance of atrial septal aneurysm (ASA) in cryptogenic stroke has not been fully studied. Therefore, we explored clinical characteristics and in-hospital recurrence in patients with ASA in cryptogenic stroke.

Methods: A multicenter observational registry of cryptogenic stroke patients was conducted. We obtained baseline characteristics, radiological and laboratory findings, and echocardiographic findings, especially of embolic sources on transesophageal echocardiography. The CHALLENGE ESUS/CS (Mechanisms of Embolic Stroke Clarified by Transesophageal Echocardiography for embolic stroke of undetermined source/cryptogenic stroke) registry was recorded at http://www.umin.ac.jp/ctr/ (UMIN000032957). Patients' clinical characteristics were compared according to the presence of ASA, and factors associated with in-hospital stroke recurrence were assessed.

Results: The study included 671 patients (age, 68.7 \pm 12.7 years; 450 males; median National Institutes of Health Stroke Scale score, 2). ASA was detected in 92 patients (14\%), displaying higher age $(72.4 \pm 11.0$ vs. 68.1 \pm 12.9 years, $p=0.004)$, reduced frequency of diabetes mellitus $(16 \%$ vs. $27 \%, p=0.030)$, higher frequency of right-to-left shunt $(66 \%$ vs. $45 \%, p<0.001)$, and in-hospital stroke recurrence $(8 \%$ vs. $3 \%, p=0.034)$. ASA was relatively associated with in-hospital recurrence (odds ratio $2.497,95 \%$ confidence interval $0.959-6.500, p=$ 0.061).

Conclusions: The CHALLENGE ESUS/CS registry indicated that ASA was not rare in cryptogenic stroke, and ASA's clinical characteristics included higher age, reduced frequency of diabetes mellitus, and increased frequency of concomitant right-to-left shunt. ASA may be related to in-hospital stroke recurrence in cryptogenic stroke.

Key words: Stroke, Cryptogenic stroke, Transesophageal echocardiography, Atrial septal aneurysm

\section{Introduction}

Cryptogenic stroke comprises $20 \%-40 \%$ of stroke cases ${ }^{1-4)}$. Cryptogenic stroke is more likely to represent embolic stroke, in which potential embolo- genic diseases are latent, rather than thrombotic infarction $^{1,5-8)}$. In 2014, embolic stroke of undetermined source (ESUS) was advocated as a new clinical entity $^{2)}$. Recent clinical trials for ESUS comparing the efficacy of direct oral anticoagulants (DOACs) with 
aspirin have failed to show any benefits of DOACs over aspirin ${ }^{9,10)}$. ESUS displays a high frequency of stroke recurrence compared to other ischemic stroke subtypes, and various underlying embologenic diseases may determine DOACs' therapeutic effects ${ }^{11,12}$. Furthermore, factors underlying embologenic diseases related to in-hospital stroke recurrence remain essentially unknown.

Atrial septal aneurysm (ASA) is an anomaly, defined as redundant and mobile interatrial septal tissue in the fossa ovalis region or the entire septum, and frequently with concomitant patent foramen ovale $(\mathrm{PFO})^{13-15)}$. The original diagnostic criteria of Trial of ORG 10172 in Acute Stroke Treatment (TOAST) Classification defined ASA as a medium risk for cardioembolism, as is $\mathrm{PFO}^{16)}$. Many studies have shown that $\mathrm{PFO}$ was more frequent in patients with cryptogenic stroke, especially young adults, than in healthy adults $5-7,17)$. Importantly, a previous study demonstrated that the coexistence of ASA and PFO potentially increased the risk of stroke recurrence, while another study reported that patients with PFO alone and patients with both PFO and ASA displayed similar occurrence rates ${ }^{8,18)}$. To date, however, few studies have focused on ASA or explored associations between ASA and cryptogenic stroke ${ }^{13,14}$. Therefore, ASA's clinical characteristics and pathogenicity of in cryptogenic stroke have not been fully elucidated.

Transesophageal echocardiography (TEE) is useful to screen for potential embolic sources in cryptogenic stroke, and TEE is superior to transthoracic echocardiography for diagnosing ASA ${ }^{14)}$. The present study used the Mechanisms of Embolic Stroke Clarified by Transesophageal Echocardiography for ESUS/ Cryptogenic Stroke (CHALLENGE ESUS/CS) registry, a multicenter registry with a comprehensive database of patients with cryptogenic stroke, who underwent TEE to identify potential embolic sources.

\section{Aim}

We explored clinical characteristics and in-hospital stroke recurrence among patients with ASA and examined the pathogenic significance of ASA for cryptogenic stroke.

\section{Methods}

Study Population

The CHALLENGE ESUS/CS registry is a multicenter, retrospective registry enrolling consecutive patients with cryptogenic stroke who underwent TEE in any of eight participating hospitals in Japan between April 2014 and December $2016^{19)}$. Inclusion criteria were: 1) within seven days of stroke onset; 2) non-lacunar stroke on neuroradiological imaging; 3) absence of arterial stenosis $\geq 50 \%$ or occlusion in a corresponding large artery; 4) absence of major embologenic cardiac diseases; and 5) absence of other determined stroke etiologies. Elicitation of medical history and diagnostic modalities, including CT/MRI, carotid duplex ultrasonography, 12-lead electrocardiography, blood examinations, and chest X-ray, were performed upon admission for CS diagnosis and enrolment in the study. This study was conducted in accordance with the Declaration of Helsinki. Institutional review boards at all eight participating centers approved the protocol. We used clinical information obtained from medical records, and the need to obtain written informed consent from each patient was, therefore, waived for this retrospective study. This study was registered at http://www.umin.ac.jp/ctr/ (UMIN000032957).

\section{Atherosclerotic Risk Factors}

Atherosclerotic risk factors were defined according to previous studies: hypertension; diabetes mellitus; dyslipidemia; current smoking status; history of ischemic heart disease; and history of ischemic stroke $^{20,21)}$. Hypertension was defined as a history of using antihypertensive agents, systolic blood pressure $>140 \mathrm{mmHg}$, or diastolic blood pressure $>90$ $\mathrm{mmHg}$ at 14 days after stroke. Diabetes mellitus was defined as the use of oral hypoglycemic agents or insulin, fasting blood glucose level $>126 \mathrm{mg} / \mathrm{dL}$, or glycosylated hemoglobin $\geq 6.5 \%$. Dyslipidemia was defined as use of antihyperlipidemic agents, serum low-density lipoprotein cholesterol $\geq 140 \mathrm{mg} / \mathrm{dL}$, high-density lipoprotein cholesterol (HDL-C) $<40 \mathrm{mg} / \mathrm{dL}$, or triglyceride $\geq 150 \mathrm{mg} / \mathrm{dL}$.

\section{TEE Study}

TEE was performed in patients who were awake and had fasted for at least $4 \mathrm{~h}$ before the examination. To examine the heart and aortic arch, a multiplane

Address for correspondence: Yuji Ueno, Department of Neurology, Juntendo University School of Medicine, 2-1-1 Hongo, Bunkyo-ku, Tokyo 113-8421, Japan

E-mail: yuji-u@juntendo.ac.jp

Received: March 13, 2020 Accepted for publication: May 28, 2020

Copyright@2021 Japan Atherosclerosis Society

This article is distributed under the terms of the latest version of CC BY-NC-SA defined by the Creative Commons Attribution License. 
probe was manipulated to provide appropriate views, including axial and sagittal images. ASA was defined as $\geq 10 \mathrm{~mm}$ excursion into either the left or right atrium, or a sum of total excursion into the left or right atrium of $\geq 15 \mathrm{~mm}^{22}$. Right-to-left shunt (RLS) was assessed by injecting agitated saline and having patients perform the Valsalva maneuver; then the numbers of microbubbles, with and without contrast agents, were compared. The number of microbubbles transiting from the right atrium to the left atrium was also counted. PFO was diagnosed when microbubbles were visualized in the left atrium within three cardiac cycles after the Valsalva maneuver. Pulmonary arteriovenous fistula ( $\mathrm{pAVF}$ ) was diagnosed when microbubbles were visualized in the left atrium more than three cardiac cycles after the Valsalva maneuver, or when microbubbles were visualized without the Valsalva maneuver. Plaque thickness was measured, and values $\geq 4 \mathrm{~mm}$ were considered to represent large aortic arch plaque. Examinations were performed by two or three experienced sonographers in each institution.

\section{Data Collection and Analyses}

Baseline clinical information, laboratory and radiological data on admission, echocardiographic findings, and clinical course on admission were collected from hospital charts or database reviews. Inhospital stroke recurrence was defined as new focal onset of neurological symptoms, corresponding to a lesion on radiological imaging. Baseline characteristics, radiological and laboratory data, echocardiographic findings, and clinical course during admission were compared according to the presence of ASA. Factors related to in-hospital stroke recurrence were analyzed. The datasets used and analyzed during the current study are available from the corresponding author upon reasonable request.

\section{Statistical Analysis}

Numerical values are reported as mean \pm standard deviation. Data were analyzed using the chi-squared test for categorical variables and the Mann-Whitney test for nonparametric analyses. All variables with values of $p<0.1$ on univariable analyses were entered into multiple logistic regression analysis to identify independent variables for patients with ASA. Predictors for in-hospital stroke recurrence were also examined, using multiple logistic regression analysis. All statistical analyses were performed using JMP Pro version 14.0.0 software (SAS Institute Inc., Cary, NC). A value of $p<0.05$ was considered statistically significant.

\section{Results}

From the eight university hospitals or stroke centers, 677 patients with cryptogenic stroke were enrolled in the CHALLENGE ESUS/CS registry. Among these, six patients were not evaluated for the presence of ASA in each TEE examination and were, thus, excluded from our study. Thus, 671 patients (age, 68.7 \pm 12.7 years; 450 males; median National Institutes of Health Stroke Scale score, 2) were finally analyzed. The median duration of hospitalization was 17 days. ASA was found in 92 patients (14\%). Table 1 shows the enrolled patients' clinical characteristics. In-hospital stroke recurrence occurred at a mean of $4.2 \pm 9.2$ days after admission. Age, sex, risk factors, National Institutes of Health Stroke Scale (NIHSS) score, and clinical course during admission were completely registered, and only a few percent of values were missing among radiological, echocardiographic, and laboratory data $(<3 \%)$.

\section{Frequency of ASA Stratified by Age}

Distributions of enrolled patients and ASA on TEE according to age are shown in Fig. 1. The number of enrolled patients with ASA increased from age $<50$ years and peaked at 70-79 years, then decreased. ASA frequency significantly increased in correlation with increasing age $(6 \%$, age $<50$ years; $8 \%, 50-59$ years; $12 \%, 60-69$ years; $16 \%, 70-79$ years; $19 \%$, $\geq$ 80 years; $p=0.040$; Fig. 1 ).

\section{Clinical Characteristics According to Presence of Asa}

Baseline characteristics, MRI and echocardiographic findings, and laboratory data were compared among 92 patients in the ASA group and 579 patients in the nonASA group (Table 1). In univariable analyses, age was higher among ASA patients $(72.4 \pm 11.0$ years vs. $68.1 \pm 12.9$ years, $p=0.004)$, and there was no significant difference in males vs. females. As vascular risk factors for atherosclerosis, the frequency of diabetes mellitus was significantly lower in patients with ASA (16\%) than in patients without ASA (27\%, $p=0.030$ ), while hypertension, dyslipidemia, cigarette smoking, chronic renal failure, coronary artery diseases, and previous history of ischemic stroke did not differ significantly between groups. In terms of MRI findings, frequencies of cortical infarction, large infarction $>3 \mathrm{~cm}$ in diameter, and intracranial arterial stenosis $(>50 \%$ stenosis in an area not relevant to the infarction area) showed no significant differences. For echocardiographic findings, frequencies of mitral and atrial regurgitation did not differ significantly between groups. RLS was more frequent in patients with ASA 
Table 1. Baseline characteristics, MRI and echocardiographic findings, laboratory data, and clinical course during admission of study subjects for atrial septal aneurysm

\begin{tabular}{|c|c|c|c|c|}
\hline \multirow[b]{2}{*}{ Characteristics } & \multirow[b]{2}{*}{$\begin{array}{c}\text { Total } \\
N=671\end{array}$} & \multicolumn{2}{|c|}{ ASA } & \multirow[b]{2}{*}{$p$} \\
\hline & & $\begin{array}{c}\text { Positive } \\
n=92(14 \%)\end{array}$ & $\begin{array}{c}\text { Negative } \\
n=579(86 \%)\end{array}$ & \\
\hline \multicolumn{5}{|l|}{ Sociodemographic } \\
\hline Age, $y$, mean $\pm S D$ & $68.7 \pm 12.7$ & $72.4 \pm 11.0$ & $68.1 \pm 12.9$ & 0.004 \\
\hline Gender, male, no (\%) & $450(67)$ & $58(63)$ & $392(68)$ & 0.377 \\
\hline \multicolumn{5}{|l|}{ Risk factors, no (\%) } \\
\hline Hypertension & $481(72)$ & $65(71)$ & $416(72)$ & 0.813 \\
\hline Diabetes mellitus & $171(25)$ & $15(16)$ & $156(27)$ & 0.030 \\
\hline Dyslipidemia & $343(51)$ & $43(47)$ & $300(52)$ & 0.366 \\
\hline Cigarette smoking & $180(27)$ & $20(22)$ & $160(28)$ & 0.236 \\
\hline Chronic kidney disease & $249(37)$ & $35(38)$ & $214(37)$ & 0.842 \\
\hline Coronary artery disease & $68(10)$ & $5(5)$ & $63(11)$ & 0.108 \\
\hline Previous history of ischemic stroke & $122(18)$ & $20(22)$ & $102(18)$ & 0.341 \\
\hline NIHSS score on admission, median (IQR) & $2(1-5)$ & $2(1-5)$ & $2(1-5)$ & 0.615 \\
\hline Carotid stenosis on duplex ultrasonography & $33(5)$ & $3(3)$ & $30(5)$ & 0.429 \\
\hline \multicolumn{5}{|l|}{ MRI, no (\%) } \\
\hline Cortical infarction $^{\mathrm{a}}$ & $533(80)$ & $70(78)$ & $463(81)$ & 0.425 \\
\hline Large infarction $\geq 3 \mathrm{~cm}$ in diameter ${ }^{\mathrm{a}}$ & $199(30)$ & $28(31)$ & $171(30)$ & 0.842 \\
\hline Intracranial arterial stenosis on MRA $\geq 50 \%$ area stenosis ${ }^{a}$ & $72(11)$ & $7(8)$ & $65(11)$ & 0.303 \\
\hline \multicolumn{5}{|l|}{ Echocardiographic findings, no (\%) } \\
\hline Mitral regurgitation ${ }^{b}$ & $357(53)$ & $48(52)$ & $309(53)$ & 0.818 \\
\hline Aortic regurgitation $^{\mathrm{c}}$ & $206(31)$ & $30(33)$ & $176(30)$ & 0.629 \\
\hline Right-to-left shunt ${ }^{\mathrm{d}}$ & $311(48)$ & $60(66)$ & $251(45)$ & $<0.001$ \\
\hline Patent foramen ovale ${ }^{\mathrm{d}}$ & $301(46)$ & $60(66)$ & $241(43)$ & $<0.001$ \\
\hline Aortic arch plaques $\geq 4 \mathrm{~mm}^{\mathrm{b}}$ & $251(37)$ & $34(37)$ & $217(38)$ & 0.914 \\
\hline \multicolumn{5}{|l|}{ Laboratory findings, ${ }^{\dagger}$} \\
\hline Leukocyte count, $\times 10^{9} / \mathrm{L}$ & $7.3 \pm 2.7$ & $6.9 \pm 2.5$ & $7.3 \pm 2.7$ & 0.080 \\
\hline HDL-C, $\mathrm{mg} / \mathrm{dL}^{\mathrm{e}}$ & $51.2 \pm 15.1$ & $50.7 \pm 14.3$ & $51.3 \pm 15.2$ & 0.746 \\
\hline $\mathrm{TG}, \mathrm{mg} / \mathrm{dL}^{\mathrm{a}}$ & $133.1 \pm 107.9$ & $115.3 \pm 69.2$ & $135.9 \pm 112.6$ & 0.087 \\
\hline Glucose, $\mathrm{mg} / \mathrm{dL}^{\mathrm{a}}$ & $131.8 \pm 51.1$ & $123.8 \pm 34.9$ & $133.1 \pm 53.2$ & 0.237 \\
\hline $\mathrm{BNP}^{\mathrm{f}}$ & $97.9 \pm 160.8$ & $61.4 \pm 68.9$ & $103.7 \pm 170.2$ & 0.204 \\
\hline D-dimer, $\mu \mathrm{g} / \mathrm{mL}$ & $2.9 \pm 16.3$ & $3.3 \pm 12.5$ & $2.8 \pm 16.9$ & 0.219 \\
\hline \multicolumn{5}{|l|}{ Clinical course during admission, no (\%) } \\
\hline Stroke recurrence & $25(4)$ & $7(8)$ & $18(3)$ & 0.034 \\
\hline Detection of PAF & $64(10)$ & $5(5)$ & $59(10)$ & 0.149 \\
\hline $\mathrm{mRS}$ on discharge $\geq 3$ & $145(22)$ & $27(29)$ & $118(20)$ & 0.052 \\
\hline
\end{tabular}

Chi-square test, and the Mann-Whitney $U$ test were used for comparison. ASA=atrial septal aneurysm; NIHSS=NIH Stroke scale; $\mathrm{IQR}=$ interquartile range; HDL-C=high-density lipoprotein cholesterol; $\mathrm{TG}=$ triglyceride; $\mathrm{BNP}=$ brain natriuretic peptide; $\mathrm{mRS}=\mathrm{modified}$ Rankin Scale; PAF = paroxysmal atrial fibrillation. Missing values: a, $n=5 ; \mathrm{b}, n=1 ; \mathrm{c}, n=2$; d, $n=20$; e, $n=8$; f, $n=92$. Chronic kidney disease was defined as eGFR $<60 \mathrm{ml} / \mathrm{min} / 1.73 \mathrm{~m}^{2}$.

$(66 \%)$ than in patients without ASA $(45 \%, p<$ $0.001)$. PFO and pAVF were found in 60 and 0 patients with ASA, respectively, while PFO and pAVF were found in 241 and 10 patients without ASA, respectively. Frequency of aortic arch plaque did not differ significantly between groups. In terms of laboratory data, no significant differences in leukocyte count, HDL-C, triglyceride or glucose levels were evi- dent.

Cryptogenic stroke patients with ASA exhibited a higher frequency of in-hospital stroke recurrence than those without ASA ( $8 \%$ vs. $3 \%, p=0.034$ ). Poor functional outcome (modified Rankin scale (mRS) score $\geq 3)$ on discharge was relatively higher $(29 \%$ vs. $20 \%, p=0.052$ ) in cryptogenic stroke patients with ASA. 


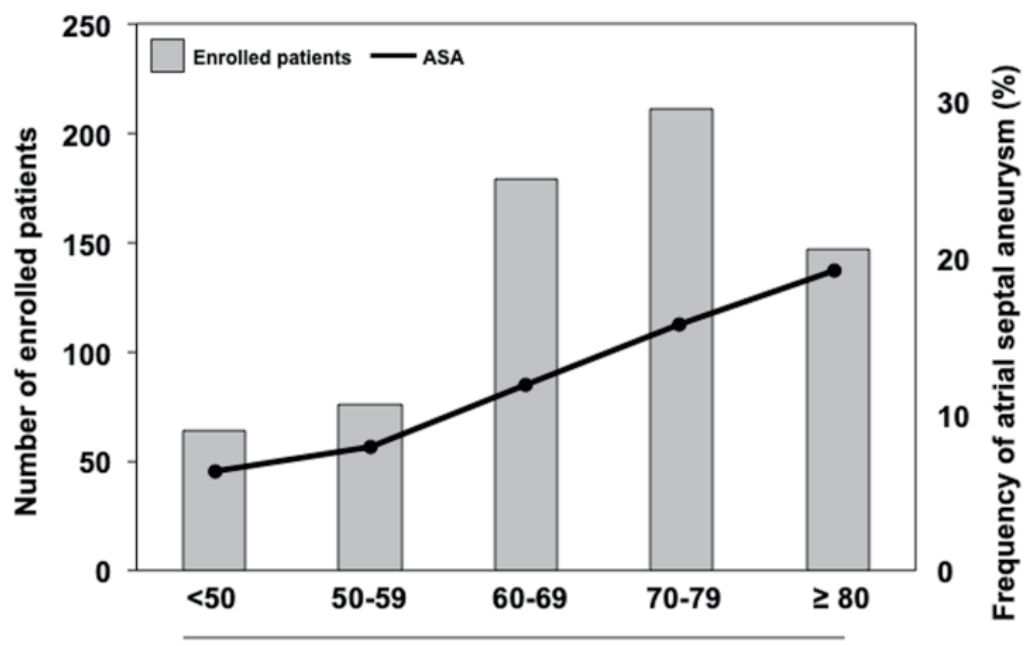

Age, years

Fig. 1. Proportion of enrolled patients and frequency of atrial septal aneurysm

Histograms and line graphs show the number of enrolled patients and frequency of atrial septal aneurysm according to age.

Table 2. Multiple logistic regression analysis predicting atrial septal aneurysm in cryptogenic stroke patients

\begin{tabular}{lccr}
\hline Variables & OR & $95 \%$ CI & \multicolumn{1}{c}{$p$} \\
\hline Age & 1.032 & $1.011-1.054$ & 0.003 \\
Diabetes mellitus & 0.521 & $0.282-0.962$ & 0.037 \\
Right-to-left shunt & 2.528 & $1.563-4.090$ & $<0.001$ \\
Leukocyte count & 1.000 & $1.000-1.000$ & 0.323 \\
Triglyceride & 0.998 & $0.995-1.001$ & 0.185 \\
In-hospital stroke recurrence & 3.255 & $1.212-8.743$ & 0.019 \\
mRS on discharge $\geq 3$ & 1.332 & $0.764-2.320$ & 0.312 \\
\hline
\end{tabular}

$\mathrm{OR}=$ odds ratio, $\mathrm{CI}=$ confidence interval.

\section{Independent Factors Associated with Patients with Asa}

Age, diabetes mellitus, RLS, leukocyte count, triglyceride, in-hospital stroke recurrence, and $\mathrm{mRS}$ score $\geq 3$ on discharge were selected for multiple logistic regression analyses to explore factors related to ASA. Age (odds ratio [OR], 1.032; 95\% confidence interval [CI], 1.011-1.054; $p=0.003)$, diabetes mellitus (OR, 0.521; 95\% CI, 0.282-0.962; $p=0.037$ ), RLS (OR, 2.528; 95\% CI, 1.563-4.090; $p<0.001$ ), and in-hospital stroke recurrence (OR, 3.255; 95\% CI, $1.212-8.743$; $p=0.019)$ were independently associated with ASA (Table 2).

\section{Association of In-Hospital Stroke Recurrence with Septal Abnormality \\ In univariable analyses, NIHSS score, mitral regurgitation, ASA, and leukocyte count tended to be}

associated with the presence of in-hospital stroke recurrence $(p<0.1)$ (Table 3). No significant differences in frequency of ASA with RLS, or ASA with large RLS ( $\geq 26$ microbubbles), were evident between patients with and without in-hospital stroke recurrence. Next, we used multiple logistic regression analysis to analyze ASA's contribution to in-hospital stroke recurrence. Multiple logistic regression analysis showed that the NIHSS score (OR, 1.074; 95\% CI, 1.024-1.127; $p=0.003$ ), ASA (OR, 2.497; 95\% CI, $0.959-6.500 ; p=0.061$ ), and D-dimer levels (OR, 1.029; 95\% CI, 0.098-1.062; $p=0.068)$ tended to be associated with in-hospital stroke recurrence (Table 4). To analyze the impact of concomitant RLS for in-hospital stroke recurrence in patients with ASA, we entered ASA with RLS and ASA without RLS into multiple logistic regression analyses, showing no significant differences (OR, 1.925; 95\% CI, 0.583- 
Table 3. Baseline characteristics, MRI and echocardiographic findings, laboratory data, and clinical course during admission of study subjects for in-hospital stroke recurrence

\begin{tabular}{|c|c|c|c|c|}
\hline \multirow[b]{2}{*}{ Characteristics } & \multirow[b]{2}{*}{$\begin{array}{c}\text { Total } \\
N=671\end{array}$} & \multicolumn{2}{|c|}{ In-hospital stroke recurrence } & \multirow[b]{2}{*}{$p$} \\
\hline & & $\begin{array}{c}\text { Positive } \\
n=25(4 \%)\end{array}$ & $\begin{array}{c}\text { Negative } \\
n=646(96 \%)\end{array}$ & \\
\hline \multicolumn{5}{|l|}{ Sociodemographic } \\
\hline Age, $y$, mean $\pm S D$ & $68.7 \pm 12.7$ & $65.3 \pm 13.9$ & $68.9 \pm 12.7$ & 0.204 \\
\hline Gender, male, no (\%) & $450(67)$ & $15(60)$ & $435(67)$ & 0.444 \\
\hline \multicolumn{5}{|l|}{ Risk factors, no (\%) } \\
\hline Hypertension & $481(72)$ & $20(80)$ & $461(71)$ & 0.347 \\
\hline Diabetes mellitus & $171(25)$ & $9(36)$ & $162(25)$ & 0.219 \\
\hline Dyslipidemia & $343(51)$ & $12(48)$ & $331(51)$ & 0.751 \\
\hline Cigarette smoking & $180(27)$ & $10(40)$ & $170(26)$ & 0.130 \\
\hline Chronic kidney disease & $249(37)$ & $11(44)$ & $238(37)$ & 0.467 \\
\hline Coronary artery disease & $68(10)$ & $4(16)$ & $64(10)$ & 0.322 \\
\hline Previous history of ischemic stroke & $122(18)$ & $2(8)$ & $120(19)$ & 0.179 \\
\hline NIHSS score on admission, median (IQR) & $2(1-5)$ & $3(2-19)$ & $2(1-5)$ & 0.028 \\
\hline Carotid stenosis on duplex ultrasonography & $33(5)$ & $1(4)$ & $32(5)$ & 0.829 \\
\hline \multicolumn{5}{|l|}{ MRI, no (\%) } \\
\hline Cortical infarction $^{\mathrm{a}}$ & $533(80)$ & $22(88)$ & $511(80)$ & 0.287 \\
\hline Large infarction $\geq 3 \mathrm{~cm}$ in diameter ${ }^{\mathrm{a}}$ & $199(30)$ & $5(20)$ & $194(30)$ & 0.271 \\
\hline Intracranial arterial stenosis on MRA $\geq 50 \%$ area stenosis $^{a}$ & $72(11)$ & $2(8)$ & $70(11)$ & 0.894 \\
\hline \multicolumn{5}{|l|}{ Echocardiographic findings, no (\%) } \\
\hline Mitral regurgitation ${ }^{b}$ & $357(53)$ & $9(36)$ & $348(54)$ & 0.078 \\
\hline Aortic regurgitation $^{c}$ & $206(31)$ & $7(28)$ & $199(31)$ & 0.758 \\
\hline ASA & $92(14)$ & $7(28)$ & $85(13)$ & 0.034 \\
\hline RLS $^{\mathrm{d}}$ & $311(48)$ & $10(42)$ & $301(48)$ & 0.542 \\
\hline ASA with RLS ${ }^{d}$ & $60(9)$ & $4(17)$ & $56(9)$ & 0.199 \\
\hline ASA with RLS with large shunt ${ }^{\mathrm{d} *}$ & $8(1)$ & $0(0)$ & $8(1)$ & 0.699 \\
\hline Aortic arch plaques $\geq 4 \mathrm{~mm}^{\mathrm{b}}$ & $251(37)$ & $7(28)$ & $244(38)$ & 0.319 \\
\hline \multicolumn{5}{|l|}{ Laboratory findings, ${ }^{\dagger}$} \\
\hline Leukocyte count, $\times 10^{9} / \mathrm{L}$ & $7.3 \pm 2.7$ & $8.1 \pm 2.7$ & $7.2 \pm 2.7$ & 0.062 \\
\hline $\mathrm{HDL}-\mathrm{C}, \mathrm{mg} / \mathrm{dL}^{\mathrm{e}}$ & $51.2 \pm 15.1$ & $48.7 \pm 17.7$ & $51.3 \pm 15.0$ & 0.288 \\
\hline $\mathrm{TG}, \mathrm{mg} / \mathrm{dL}^{\mathrm{a}}$ & $133.1 \pm 107.9$ & $121.0 \pm 79.4$ & $133.5 \pm 108.9$ & 0.520 \\
\hline Glucose, $\mathrm{mg} / \mathrm{dL}^{\mathrm{a}}$ & $131.8 \pm 51.1$ & $149.6 \pm 92.5$ & $131.2 \pm 48.9$ & 0.278 \\
\hline BNP, $\mathrm{pg} / \mu \mathrm{l}^{\mathrm{f}}$ & $97.9 \pm 160.8$ & $78.7 \pm 89.0$ & $98.7 \pm 163.2$ & 0.844 \\
\hline D-dimer, $\mu \mathrm{g} / \mathrm{mL}$ & $2.9 \pm 16.3$ & $21.7 \pm 78.2$ & $2.2 \pm 5.9$ & 0.087 \\
\hline
\end{tabular}

Chi-square test, and the Mann-Whitney $U$ test were used for comparison. ASA=atrial septal aneurysm; NIHSS=NIH Stroke scale; $\mathrm{IQR}=$ interquartile range; $\mathrm{RLS}=$ Right-to-left shunt; HDL-C = high-density lipoprotein cholesterol; $\mathrm{TG}=$ triglyceride; $\mathrm{BNP}=$ brain natriuretic peptide. Missing values: a, $n=5 ; \mathrm{b}, n=1$;,$n=2$; $\mathrm{d}, n=20$; e, $n=8 ; \mathrm{f}, n=92 .{ }^{*}=$ more than $\geq 26$ microbubbles. Chronic kidney disease was defined as eGFR $<60 \mathrm{ml} / \mathrm{min} / 1.73 \mathrm{~m}^{2}$.

Table 4. Multiple logistic regression analysis predicting in-hospital stroke recurrence in cryptogenic stroke patients

\begin{tabular}{lccc}
\hline Variables & OR & $95 \%$ CI & $p$ \\
\hline NIHSS score on admission & 1.074 & $1.024-1.127$ & 0.003 \\
Mitral regurgitation & 0.567 & $0.238-1.354$ & 0.202 \\
ASA & 2.497 & $0.959-6.500$ & 0.061 \\
Leukocyte count & 1.000 & $1.000-1.000$ & 0.550 \\
D-dimer & 1.029 & $0.998-1.062$ & 0.068 \\
\hline
\end{tabular}

$\mathrm{OR}=$ odd ratio, $\mathrm{CI}=$ confidence interval, $\mathrm{NIHSS}=\mathrm{NIH}$ Stroke scale, $\mathrm{ASA}=$ atrial septal aneurysm. 
6.358; $p=0.283$; OR 2.934; 95\% CI $0.774-11.125$; $p=0.114)$.

\section{Discussion}

The present study used the CHALLENGE ESUS/CS registry, enrolling a number of cryptogenic stroke patients who underwent TEE to elucidate underlying embolic sources and comprehensive clinical data, and displayed that ASA accounted for 14\% of cryptogenic strokes. Clinical characteristics of cryptogenic stroke with ASA included higher age, lower frequency of diabetes mellitus, higher frequency of concomitant RLS, and higher frequencies of in-hospital recurrent stroke. Furthermore, ASA was shown to be comparatively associated with stroke recurrence during hospitalization.

The incidence of ASA is reportedly $0.2 \%-4 \%$ on transthoracic echocardiography, increasing to $2 \%-8 \%$ on TEE ${ }^{13-15)}$. In cryptogenic stroke, the frequency of ASA was increased to $6.4 \%-39.1 \%^{7,23-25)}$. ASA is considered redundant in the fossa ovalis region and mobile interatrial septal tissue with phasic bulging during the cardiac cycle ${ }^{13,15)}$. Interestingly, the CHALLENGE ESUS/CS registry showed that ASA frequency increased with aging. Large-scale autopsy and echocardiographic studies have shown ASA in a wide age range, with a higher frequency among middleaged patients ${ }^{13,14,26)}$. Although ASA is generally considered a congenital malformation in the septum primum layer of the interatrial septum, its pathogenesis has yet to be elucidated.

The current study made another crucial finding: ASA was relatively associated with in-hospital stroke recurrence in cryptogenic stroke. Some possible explanations for ASA as a cause of stroke recurrence may be suggested from CHALLEGE ESUS/CS. First, ASA itself can be a potential source of embolism for recurrent stroke. ASA with thromboembolic events has been associated with a higher frequency of intra-atrial thrombus ${ }^{14,27)}$. In surgical and autopsy studies, thrombus has been confirmed in the aneurysmal sacs of $\mathrm{ASA}^{26,28)}$. Thus, newly reformatted thrombus or undetected thrombus on TEE, adhering to the aneurysm or in the left atrium following acute stroke, may cause early stroke recurrence. Second, ASA frequency correlated with increased age and other embologenic diseases, such as covert atrial fibrillation (AF) undetected during admission, or systemic atherosclerosis due to age, might have been involved. In the current study, paroxysmal AF was fundamentally investigated by 12-lead electrocardiography on admission, cardiac monitoring, and 24-h Holter monitoring during admission. According to recent progress in detecting paroxysmal AF, long-term electrocardiography to elucidate the association of ASA and covert AF is impor$\operatorname{tant}^{29)}$. Third, ASA might induce modifications to the electrophysiological substrate and physiological dysfunction in the left atrium, leading to atrial vulnerability ${ }^{30-32)}$. However, there is little evidence associating atrial vulnerability with early stroke recurrence. In general, the coexistence of PFO and ASA increases the risk of stroke recurrence by $7.6 \%-15.2 \%$ during longterm follow-up of cryptogenic stroke ${ }^{8,33-35)}$. To date, in-hospital stroke recurrence has been essentially unknown among cryptogenic stroke. Our registry focused on stroke recurrence during hospitalization for cryptogenic stroke in terms of potential embolic sources and, for the first time, revealed that ASA might represent a cause of in-hospital stroke recurrence independent from concomitant RLS.

In the current study, acute therapy for cryptogenic stroke was performed by stroke physicians in participating hospitals according to the current stroke guideline and their best medical judgment, assuming that most patients with cryptogenic stroke could be treated with antiplatelet agents ${ }^{1,36,37)}$. Interestingly, our data also showed that high NIHSS score (median, 3) was related to in-hospital stroke recurrence. In a subgroup analysis of the Clopidogrel in high-risk patients with Acute Non-disabling Cerebrovascular Events (CHANCE) trial, which enrolled patients with minor noncardioembolic stroke or transient ischemic attack, high NIHSS score (2-3) was associated with stroke recurrence within 90 days after treatment with dual antiplatelet therapy ${ }^{38)}$. Our data also indicated that high D-dimer levels were related to in-hospital stroke recurrence, possibly because an underlying specific pathogenesis refractory to antiplatelet therapy, such as coagulopathy or Trousseau syndrome, might be present in cryptogenic stroke patients with such clinical features ${ }^{39,40)}$. On the other hand, there is little or no evidence on secondary prevention in stroke patients with ASA, although treatment with anticoagulants may be a reasonable approach to dissolve the thrombus or prevent fibrin adherence to the septal wall. Furthermore, the long-term prognosis of cryptogenic stroke patients with and without ASA is unknown. Taken together, considering the mechanisms causing in-hospital recurrent stroke and optimal antithrombotic therapy for ASA, high NIHSS score, and D-dimer levels, further studies with a prospective design, larger sample size, and long-term monitoring may be required to clarify its pathogenesis.

This study has some limitations that must be considered when interpreting the results. First, this was a retrospective study, and treatments were nonrandomized. Medications, especially acute antithrombotic 
treatments, might, in turn, have affected in-hospital stroke recurrence. Second, regarding TEE examinations, selection of cryptogenic stroke patients for TEE in participating hospitals, and the lack of data on TEE timing during admission (especially in patients with in-hospital stroke recurrence) were certainly biases in the current study. Third, a small proportion of radiological, echocardiographic, and laboratory data (especially for brain natriuretic peptide level) were missing, and relatively few patients with ASA experienced recurrent stroke.

\section{Conclusion}

The CHALLENGE ESUS/CS registry enrolled a large number of cryptogenic stroke patients, in whom potential embolic etiologies were identified on TEE. The current results provide new insights in that clinical characteristics of cryptogenic stroke with ASA include older age, lower frequencies of diabetes mellitus, and higher frequency of concomitant RLS. These findings suggested that ASA might be related to inhospital stroke recurrence in cryptogenic stroke. Our data offer a first insight into elucidating ASA's clinical characteristics in cryptogenic stroke with multicenter registries. However, the pathological contribution of ASA remained, and further study is warranted.

\section{Acknowledgements}

None.

\section{Funding}

The authors have no specific grants to declare in association with this research from any funding agency in the public, commercial or not-for-profit sectors.

\section{Potential Conflicts of Interest}

Y.U. received lecture fees from OHARA Pharmaceutical Co., Ltd., and research funds from BristolMyers Squibb. H.T. received lecture fees from Pfizer Japan Inc. and Daiichi Sankyo Co., Ltd. M.K. received lecture fees from Bayer Pharmaceutical Co. M.I. received lecture fees from Shimadzu Corporation, Otsuka Pharmaceutical, Bristol-Myers Squibb, and Boehringer Ingelheim GmbH. K.H. received lecture fees from MSD Co., Ltd., Eisai Co., Ltd., Otsuka Pharmaceutical Co., Ltd., Takeda Pharmaceutical Co., Ltd., Pfizer Japan Inc., Novartis Pharma K.K., and AbbVie GK, and research funds from Eisai Co., Ltd., Pfizer Japan Inc., Novartis Pharma K.K., Takeda Pharmaceutical Co., Ltd., TAIYO Co., Ltd., Kyowa Min- ami Hospital, Shirasawa Hospital, Shiobara Onsen Hospital, Utsunomiya Chuo Hospital, Nishikata Hospital, and Moka. Hospital. K.T. received lecture fees from Bayer Pharmaceutical Co., Boehringer Ingelheim, Bristol-Myers Squibb, and Daiichi Sankyo Co., Ltd. Y.H. received lecture fees from Bayer Pharmaceutical Co. N.H. was an advisory member of Dai-Nippon Sumitomo Pharma Co., Ltd., Hisamitsu Pharmaceutical Co., Inc, Biogen Idec Japan Ltd., received lecture fees from Dai-Nippon Sumitomo Pharma Co., Ltd., Otsuka Pharmaceutical, Co., Ltd., Takeda Pharmaceutical Co., Ltd., Kyowa Hakko-Kirin Co., Ltd., FP Pharmaceutical Corporation, Eisai Co., Ltd., and Novartis Pharma K.K., AbbVie, and received departmental endowments by commercial entities from Kyowa Hakko-Kirin Co., Ltd., Nippon Boehringer Ingelheim, Co., Ltd., AbbVie GK, FP Pharmaceutical Corporation, Otsuka Pharmaceutical, Co., Ltd., DaiNippon Sumitomo Pharma Co., Ltd., Eisai Co., Ltd., Nihon Medi-physics Co., Ltd., Asahi Kasei Medical Co., Ltd., Ono Pharmaceutical Co., Ltd., MiZ Co., Ltd., AbbVie GK, OHARA Pharmaceutical Co., Ltd., Nihon Pharmaceutical Co., Ltd., Mitsubishi Tanabe Pharma Corporation, Boston Scientific Corporation, and Medtronic Inc. T.U. received lecture fees from Daiichi Sankyo Co., Ltd., Boehringer Ingelheim, Otsuka Pharmaceutical Co., Ltd., Bayer Pharmaceutical Co., AstraZeneca K.K., and AbbVie GK., and research funds from Otsuka Pharmaceutical Co., Ltd., Astellas Pharma Inc., Bayer Pharmaceutical Co. Ltd., AbbVie GK., and Eisai Co., Ltd. The remaining authors report no conflicts of interest.

\section{References}

1) Hart RG, Catanese L, Perera KS, Ntaios G and Connolly SJ: Embolic Stroke of Undetermined Source: A Systematic Review and Clinical Update. Stroke, 2017; 48: 867872

2) Hart RG, Diener HC, Coutts SB, Easton JD, Granger CB, O’Donnell MJ, Sacco RL, Connolly SJ and Cryptogenic Stroke EIWG: Embolic strokes of undetermined source: the case for a new clinical construct. Lancet Neurol, 2014; 13: 429-438

3) Sacco RL, Diener HC, Yusuf S, Cotton D, Ounpuu S, Lawton WA, Palesch Y, Martin RH, Albers GW, Bath P, Bornstein N, Chan BP, Chen ST, Cunha L, Dahlof B, De Keyser J, Donnan GA, Estol C, Gorelick P, Gu V, Hermansson K, Hilbrich L, Kaste M, Lu C, Machnig T, Pais P, Roberts R, Skvortsova V, Teal P, Toni D, Vandermaelen C, Voigt T, Weber M, Yoon BW and Group PRS: Aspirin and extended-release dipyridamole versus clopidogrel for recurrent stroke. N Engl J Med, 2008; 359: 1238-1251

4) Mohr JP, Thompson JL, Lazar RM, Levin B, Sacco RL, Furie KL, Kistler JP, Albers GW, Pettigrew LC, Adams HP, Jr., Jackson CM, Pullicino P and Warfarin-Aspirin 
Recurrent Stroke Study G: A comparison of warfarin and aspirin for the prevention of recurrent ischemic stroke. $\mathrm{N}$ Engl J Med, 2001; 345: 1444-1451

5) Di Tullio M, Sacco RL, Gopal A, Mohr JP and Homma S: Patent foramen ovale as a risk factor for cryptogenic stroke. Ann Intern Med, 1992; 117: 461-465

6) de Belder MA, Tourikis L, Leech G and Camm AJ: Risk of patent foramen ovale for thromboembolic events in all age groups. Am J Cardiol, 1992; 69: 1316-1320

7) Handke M, Harloff A, Olschewski M, Hetzel A and Geibel A: Patent foramen ovale and cryptogenic stroke in older patients. N Engl J Med, 2007; 357: 2262-2268

8) Mas JL, Arquizan C, Lamy C, Zuber M, Cabanes L, Derumeaux G, Coste J, Patent Foramen $\mathrm{O}$ and Atrial Septal Aneurysm Study G: Recurrent cerebrovascular events associated with patent foramen ovale, atrial septal aneurysm, or both. N Engl J Med, 2001; 345: 1740-1746

9) Diener HC, Easton JD, Granger CB, Cronin L, Duffy C, Cotton D, Brueckmann M, Sacco RL and Investigators R-SE: Design of Randomized, double-blind, Evaluation in secondary Stroke Prevention comparing the EfficaCy and safety of the oral Thrombin inhibitor dabigatran etexilate vs. acetylsalicylic acid in patients with Embolic Stroke of Undetermined Source (RE-SPECT ESUS). Int J Stroke, 2015; 10: 1309-1312

10) Hart RG, Sharma M, Mundl H, Kasner SE, Bangdiwala SI, Berkowitz SD, Swaminathan B, Lavados P, Wang Y, Wang Y, Davalos A, Shamalov N, Mikulik R, Cunha L, Lindgren A, Arauz A, Lang W, Czlonkowska A, Eckstein J, Gagliardi RJ, Amarenco P, Ameriso SF, Tatlisumak T, Veltkamp R, Hankey GJ, Toni D, Bereczki D, Uchiyama S, Ntaios G, Yoon BW, Brouns R, Endres M, Muir KW, Bornstein N, Ozturk S, O’Donnell MJ, De Vries Basson MM, Pare G, Pater C, Kirsch B, Sheridan P, Peters G, Weitz JI, Peacock WF, Shoamanesh A, Benavente OR, Joyner C, Themeles E, Connolly SJ and Investigators NE: Rivaroxaban for Stroke Prevention after Embolic Stroke of Undetermined Source. N Engl J Med, 2018; 378: 2191-2201

11) Ntaios G, Papavasileiou V, Milionis H, Makaritsis K, Vemmou A, Koroboki E, Manios E, Spengos K, Michel P and Vemmos K: Embolic Strokes of Undetermined Source in the Athens Stroke Registry: An Outcome Analysis. Stroke, 2015; 46: 2087-2093

12) Kasner SE, Swaminathan B, Lavados P, Sharma M, Muir K, Veltkamp R, Ameriso SF, Endres M, Lutsep H, Messe SR, Spence JD, Nedeltechev K, Perera K, Santo G, Olavarria V, Lindgren A, Bangdiwala S, Shoamanesh A, Berkowitz SD, Mundl H, Connolly SJ, Hart RG and Investigators NE: Rivaroxaban or aspirin for patent foramen ovale and embolic stroke of undetermined source: a prespecified subgroup analysis from the NAVIGATE ESUS trial. Lancet Neurol, 2018; 17: 1053-1060

13) Belkin RN, Waugh RA and Kisslo J: Interatrial shunting in atrial septal aneurysm. Am J Cardiol, 1986; 57: 310312

14) Mugge A, Daniel WG, Angermann C, Spes C, Khandheria BK, Kronzon I, Freedberg RS, Keren A, Denning K, Engberding $\mathrm{R}$ and et al.: Atrial septal aneurysm in adult patients. A multicenter study using transthoracic and transesophageal echocardiography. Circulation, 1995; 91:
2785-2792

15) Hanley PC, Tajik AJ, Hynes JK, Edwards WD, Reeder GS, Hagler DJ and Seward JB: Diagnosis and classification of atrial septal aneurysm by two-dimensional echocardiography: report of 80 consecutive cases. J Am Coll Cardiol, 1985; 6: 1370-1382

16) Adams HP, Jr., Bendixen BH, Kappelle LJ, Biller J, Love BB, Gordon DL and Marsh EE, 3rd: Classification of subtype of acute ischemic stroke. Definitions for use in a multicenter clinical trial. TOAST. Trial of Org 10172 in Acute Stroke Treatment. Stroke, 1993; 24: 35-41

17) Lamy C, Giannesini C, Zuber M, Arquizan C, Meder JF, Trystram D, Coste J and Mas JL: Clinical and imaging findings in cryptogenic stroke patients with and without patent foramen ovale: the PFO-ASA Study. Atrial Septal Aneurysm. Stroke, 2002; 33: 706-711

18) Homma S, Sacco RL, Di Tullio MR, Sciacca RR, Mohr JP and Investigators PFOiCSS: Effect of medical treatment in stroke patients with patent foramen ovale: patent foramen ovale in Cryptogenic Stroke Study. Circulation, 2002; 105: 2625-2631

19) Ueno Y, Tateishi Y, Doijiri R, Kuriki A, Shimizu T, Kikuno M, Shimada Y, Takekawa H, Yamaguchi E, Koga M, Kamiya Y, Ihara M, Tsujino A, Hirata K, Toyoda K, Hasegawa Y, Hattori $\mathrm{N}$ and Urabe T: Large aortic arch plaques correlate with CHADS2 and CHA2DS2-VASc scores in cryptogenic stroke. Atherosclerosis, 2019; 284: 181-186

20) Ueno $Y$, Iguchi $Y$, Inoue $T$, Shibazaki $K$, Urabe $T$ and Kimura K: Paradoxical brain embolism may not be uncommon-prospective study in acute ischemic stroke. J Neurol, 2007; 254: 763-766

21) Tanaka Y, Ueno Y, Miyamoto N, Shimada Y, Tanaka R, Hattori $\mathrm{N}$ and Urabe T: Patent foramen ovale and atrial septal aneurysm can cause ischemic stroke in patients with antiphospholipid syndrome. J Neurol, 2013; 260: 189196

22) Silvestry FE, Cohen MS, Armsby LB, Burkule NJ, Fleishman CE, Hijazi ZM, Lang RM, Rome JJ, Wang Y, American Society of E, Society for Cardiac A and Interventions: Guidelines for the Echocardiographic Assessment of Atrial Septal Defect and Patent Foramen Ovale: From the American Society of Echocardiography and Society for Cardiac Angiography and Interventions. J Am Soc Echocardiogr, 2015; 28: 910-958

23) Cabanes L, Mas JL, Cohen A, Amarenco P, Cabanes PA, Oubary P, Chedru F, Guerin F, Bousser MG and de Recondo J: Atrial septal aneurysm and patent foramen ovale as risk factors for cryptogenic stroke in patients less than 55 years of age. A study using transesophageal echocardiography. Stroke, 1993; 24: 1865-1873

24) Dawn B, Hasnie AM, Calzada N, Longaker RA and Stoddard MF: Transesophageal echocardiography impacts management and evaluation of patients with stroke, transient ischemic attack, or peripheral embolism. Echocardiography, 2006; 23: 202-207

25) Labovitz AJ, Camp A, Castello R, Martin TJ, Ofili EO, Rickmeyer N, Vaughn M and Gomez CR: Usefulness of transesophageal echocardiography in unexplained cerebral ischemia. Am J Cardiol, 1993; 72: 1448-1452

26) Silver MD and Dorsey JS: Aneurysms of the septum pri- 
mum in adults. Arch Pathol Lab Med, 1978; 102: 62-65

27) Schneider B, Hanrath $P$, Vogel $P$ and Meinertz $T$ : Improved morphologic characterization of atrial septal aneurysm by transesophageal echocardiography: relation to cerebrovascular events. J Am Coll Cardiol, 1990; 16: 1000-1009

28) Grosgogeat Y, Lhermitte F, Carpentier A, Facquet J, Alhomme P and Tran T: [Aneurysm of the interauricular septum revealed by a cerebral embolism]. Arch Mal Coeur Vaiss, 1973; 66: 169-177

29) Sanna T, Diener HC, Passman RS, Di Lazzaro V, Bernstein RA, Morillo CA, Rymer MM, Thijs V, Rogers T, Beckers F, Lindborg K, Brachmann J and Investigators CA: Cryptogenic stroke and underlying atrial fibrillation. N Engl J Med, 2014; 370: 2478-2486

30) Janion M, Kurzawski J, Sielski J, Ciuraszkiewicz K, Sadowski $\mathrm{M}$ and Radomska E: Dispersion of P wave duration and $\mathrm{P}$ wave vector in patients with atrial septal aneurysm. Europace, 2007; 9: 471-474

31) Rigatelli G, Aggio S, Cardaioli P, Braggion G, Giordan M, Dell'avvocata F, Chinaglia M, Rigatelli G, Roncon L and Chen JP: Left atrial dysfunction in patients with patent foramen ovale and atrial septal aneurysm: an alternative concurrent mechanism for arterial embolism? JACC Cardiovasc Interv, 2009; 2: 655-662

32) Berthet K, Lavergne T, Cohen A, Guize L, Bousser MG, Le Heuzey JY and Amarenco P: Significant association of atrial vulnerability with atrial septal abnormalities in young patients with ischemic stroke of unknown cause. Stroke, 2000; 31: 398-403

33) Mas JL, Derumeaux G, Guillon B, Massardier E, Hosseini H, Mechtouff L, Arquizan C, Bejot Y, Vuillier F, Detante O, Guidoux C, Canaple S, Vaduva C, DequatrePonchelle N, Sibon I, Garnier P, Ferrier A, Timsit S, Robinet-Borgomano E, Sablot D, Lacour JC, Zuber M, Favrole P, Pinel JF, Apoil M, Reiner P, Lefebvre C, Guerin P, Piot C, Rossi R, Dubois-Rande JL, Eicher JC, Meneveau N, Lusson JR, Bertrand B, Schleich JM, Godart F, Thambo JB, Leborgne L, Michel P, Pierard L, Turc G, Barthelet M, Charles-Nelson A, Weimar C, Moulin T, Juliard JM, Chatellier G and Investigators C: Patent Foramen Ovale Closure or Anticoagulation vs. Antiplatelets after Stroke. N Engl J Med, 2017; 377: 1011-1021

34) Saver JL, Carroll JD, Thaler DE, Smalling RW, MacDonald LA, Marks DS, Tirschwell DL and Investigators R: Long-Term Outcomes of Patent Foramen Ovale Closure or Medical Therapy after Stroke. N Engl J Med, 2017; 377: 1022-1032

35) Sondergaard L, Kasner SE, Rhodes JF, Andersen G, Iversen HK, Nielsen-Kudsk JE, Settergren M, Sjostrand C, Roine RO, Hildick-Smith D, Spence JD, Thomassen $\mathrm{L}$ and Gore RCSI: Patent Foramen Ovale Closure or Antiplatelet Therapy for Cryptogenic Stroke. N Engl J Med, 2017; 377: 1033-1042

36) Powers WJ, Rabinstein AA, Ackerson T, Adeoye OM, Bambakidis NC, Becker K, Biller J, Brown M, Demaerschalk BM, Hoh B, Jauch EC, Kidwell CS, Leslie-Mazwi TM, Ovbiagele B, Scott PA, Sheth KN, Southerland AM, Summers DV, Tirschwell DL and American Heart Association Stroke C: 2018 Guidelines for the Early Management of Patients With Acute Ischemic Stroke: A Guideline for Healthcare Professionals From the American Heart Association/American Stroke Association. Stroke, 2018; 49: e46-e110

37) Kernan WN, Ovbiagele B, Black HR, Bravata DM, Chimowitz MI, Ezekowitz MD, Fang MC, Fisher M, Furie KL, Heck DV, Johnston SC, Kasner SE, Kittner SJ, Mitchell PH, Rich MW, Richardson D, Schwamm LH, Wilson JA, American Heart Association Stroke Council CoC, Stroke Nursing CoCC and Council on Peripheral Vascular D: Guidelines for the prevention of stroke in patients with stroke and transient ischemic attack: a guideline for healthcare professionals from the American Heart Association/American Stroke Association. Stroke, 2014; 45: 2160-2236

38) Wangqin R, Wang X, Wang Y, Xian Y, Zhao X, Liu L, Li $\mathrm{H}$, Meng $\mathrm{X}$ and Wang Y: Risk factors associated with 90-day recurrent stroke in patients on dual antiplatelet therapy for minor stroke or high-risk TIA: a subgroup analysis of the CHANCE trial. Stroke Vasc Neurol, 2017; 2: $176-183$

39) Kamel H, Merkler AE, Iadecola C, Gupta A and Navi BB: Tailoring the Approach to Embolic Stroke of Undetermined Source: A Review. JAMA Neurol, 2019; 76: $855-861$

40) Tsushima M, Metoki N, Hagii J, Saito S, Shiroto H, Yasujima M, Kato T, Kudo N, Toyama Y, Yokono Y, Nozaka M, Kawamura Y, Nakata M and Tomita H: D-dimer and C-reactive Protein as Potential Biomarkers for Diagnosis of Trousseau's Syndrome in Patients with Cerebral Embolism. J Stroke Cerebrovasc Dis, 2020; 29: 104534 